\title{
The functional sites of miRNAs and IncRNAs in gastric carcinogenesis
}

\author{
Xiangxiang Wan • Xiaoyun Ding • Shengcan Chen • \\ Haojun Song • Haizhong Jiang • Ying Fang • Peifei Li • \\ Junming Guo
}

Received: 30 October 2014 / Accepted: 19 January 2015 / Published online: 1 February 2015

(C) The Author(s) 2015. This article is published with open access at Springerlink.com

\begin{abstract}
Gastric cancer is one of the most common malignant diseases and has one of the highest mortality rates worldwide. Its molecular mechanisms are poorly understood. Recently, the functions of non-coding RNAs (ncRNAs) in gastric cancer have attracted wide attention. Although the expression levels of various ncRNAs are different, they may work together in a network and contribute to gastric carcinogenesis by altering the expression of oncogenes or tumor suppressor genes. They affect the cell cycle, apoptosis, motility, invasion, and metastasis. Dysregulated microRNAs (miRNAs) and long non-coding RNAs (lncRNAs), including miR-21, miR-106, H19, and ANRIL, directly or indirectly regulate carcinogenic factors or signaling pathways such as PTEN, CDK, caspase, E-cadherin, Akt, and P53. Greater recognition of the roles of miRNAs and lncRNAs in gastric carcinogenesis can provide new insight into the mechanisms of tumor development and identify targets for anticancer drug development.
\end{abstract}

Keywords miRNAs $\cdot \operatorname{lncRNAs} \cdot$ Gastric carcinogenesis · Mechanisms

\section{Introduction}

Gastric cancer (GC) is the fourth most frequent malignancy, with most patients being diagnosed in advanced stages with

X. Wan $\cdot$ X. Ding $(\bowtie) \cdot$ H. Song $\cdot$ H. Jiang $\cdot$ Y. Fang

Department of Gastroenterology, Ningbo First Hospital,

No. 59 Liuting Street, Ningbo 315010, China

e-mail: dyyyding@126.com

S. Chen $\cdot$ P. Li $\cdot$ J. Guo

Department of Biochemistry and Molecular Biology,

Zhejiang Provincial Key Laboratory of Pathophysiology,

Ningbo University School of Medicine, Ningbo 315211, China limited treatment options. GC continues to present a major clinical challenge [1] and ranks as the second leading cause of cancer-related death [2]. The development of GC is a complex and multistep process. It results from a combination of environmental factors and the accumulation of generalized and specific genetic alterations. Predisposing factors include Helicobacter pylori (H. pylori) infection, high salt intake, smoking, and familial genetic components [1].

Non-coding RNAs (ncRNAs) are generally divided into three major classes based on the following sizes : (1) short ncRNAs, including the much-studied microRNAs (miRNAs), which mediate posttranscriptional gene silencing, and Piwiinteracting RNAs (piRNAs); (2) mid-size ncRNAs, such as small nucleolar RNAs (snoRNAs); and (3) long non-coding RNAs (lncRNAs), which act as signals, guides, or scaffolds to chromatin to regulate the expression of target genes [3].

Over the past few years, increasing studies have demonstrated that miRNAs [4] and lncRNAs [5] could function as oncogenes or tumor suppressor genes. In GC, many miRNAs and lncRNAs are dysregulated and can regulate gene expression and biological functions cooperatively. Some play key roles in cellular processes including the cell cycle, apoptosis, and metastasis $[2,6]$.

\section{ncRNAs associated with the cell cycle in GC}

The cell cycle includes four phases: (1) G1 (Gap1), (2) S (DNA synthesis), (3) G2 (Gap2), and (4) M (mitosis). Initiation of each phase requires Cyclin/Cyclin-dependent kinase (CDK) complexes, which are assisted by several protein kinases [7]. In late G1, Cyclin D-CDK4/6 activity begins to decrease, and Cyclin E-CDK2 activity rises. Cyclin E-CDK2 can increase E2F by inhibiting $\mathrm{Rb}$ (retinoblastoma), which hampers E2F, and upregulating a number of targets important for S-phase entry and progression. During early S-phase, with 
the decomposition of Cyclin E, Cyclin A complexes with CDK2 to drive progression through S-phase into G2. From mid-G2 onwards, CDK2 activity decreases and Cyclin A associates with CDK1. Finally, to enter M-phase, Cyclin B complexes with CDK1 and phosphorylates their targets. In late Mphase, following cytokinesis, Cyclin B is degraded, indicating the start of the next round of the cycle [8]. CDK activity is modulated by CDKs including CAK (a complex of CDK7 and Cyclin $\mathrm{H}$ ) by CDK phosphatases (CDC25 phosphatases) that activate the Cyclin $\mathrm{B} / \mathrm{CDK} 1$ complex to promote mitotic entry, and by CDK inhibitors (CDKIs) including the Ink4 $\left(\mathrm{p} 15^{\text {Ink } 4 \mathrm{~b}}, \mathrm{p} 16^{\text {Ink4a }}, \mathrm{p} 18^{\text {Ink4c }}\right.$, and $\left.\mathrm{p} 19^{\text {Ink4d }}\right)$ and Cip/Kip (p21 ${ }^{\mathrm{Cip} 1}, \mathrm{p} 27^{\mathrm{Kip} 1}$, and $\mathrm{p} 57^{\mathrm{Kip} 2}$ ) families [9]. As p53 upregulates $\mathrm{p} 21^{\mathrm{Cip} 1}$, $\mathrm{p} 53$-mediated tumor suppressor pathways also block the cell cycle [8]. Myc can both activate and repress the expression of Cyclin and CDK genes [9]. Interestingly, in GC, miRNAs and lncRNAs are associated with almost all the cell cycle regulatory sites. (Figs. 1 and 2)

ncRNAs affect the Akt pathway in the cell cycle

\section{Effect upstream of the Akt axis}

The Akt-FOXO1-p21 Cip1/p2 $7^{\text {Kip1 }}$ axis plays an important role in the cell cycle (Fig. 1). Akt activation leads to the inhibition of FOXO1 and, consequently, downregulates the expression of $\mathrm{p} 21^{\mathrm{Cip} 1}$ and $\mathrm{p} 27^{\mathrm{Kip} 1}$. Decreased miR-124 in GC can inhibit the cell cycle by downregulating SPHK1, which triggers this axis [10]. Another important cell cycle signaling pathway is the PI3K-Akt-p53-Cyclin D1/cdc25A axis, which is induced by PTEN deficiency. As the intermediate link, miR-365 is indirectly suppressed by Akt by decreasing p 53 abundance. In turn, reduced miR-365 leads to the upregulation of Cyclin D1 and cdc25A [11]. In addition to miR-124 and miR-365, many other miRNAs and lncRNAs may influence the cell cycle by regulating upstream components of the Akt pathway in GC (Fig. 1). miR-21 promotes cell proliferation by targeting PTEN [12]. PTEN downregulation promotes Akt signaling and results in increased NF- $\mathrm{KB}$ [13]. In GC, both ROS [14] and NF- $\mathrm{KB}$ [15] can increase the level of miR-21. Meanwhile, miR-362 upregulation activates NF-kB signaling by repressing CYLD [16]. In addition, nicotine enhances the binding of NF- $\mathrm{KB}$ to the miR-21 promoter. The activation of COX-2/prostaglandin E2 (PGE2) signaling in response to nicotine is mediated by the action of the prostaglandin $\mathrm{E}$ receptors (EP2 and EP4), which impair nicotine-mediated NF- $\mathrm{KB}$ activity [15]. Furthermore, activated NF-kB upregulates the expression of Cox-2 [13], thus forming a complex regulatory network among miR-21, Akt, and NF-kB in the progress of gastric carcinogenesis. Receptor tyrosine kinases (RTKs) regulate a key initiator of phosphoinositide-3 kinase (PI3K)-Akt through the RAS signaling pathway [17]. As an RTK, ERBB2 is upregulated and inversely correlated with miR-125a-5p expression in GC. Both ERBB2 and its primary downstream signaling pathway through Akt are suppressed by miR-125a5p [18]. miR-338 reduced in GC decreases Akt phosphorylation by attenuating the expression of NRP1, a receptor for the vascular endothelial growth factor (VEGF) isoform VEGF-

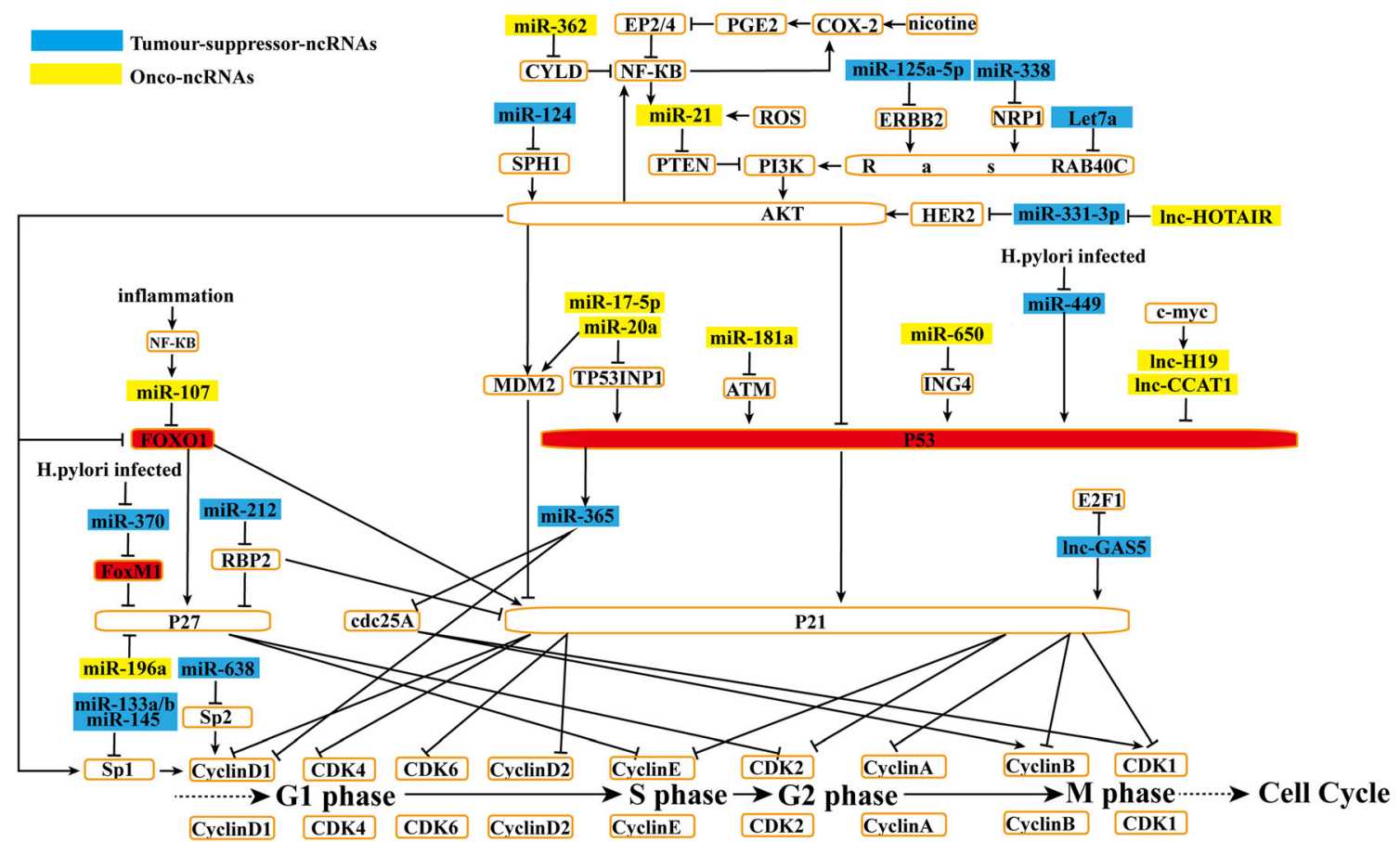

Fig 1 ncRNAs affect Akt pathway in cell cycle. MiRNAs and lncRNAs affect gastric cancer cell cycle progression. By regulating Akt pathway, onconcRNAs promote gastric cancer cell growth. Conversely, tumor suppressor ncRNAs suppress the gastric cancer cell cycle 


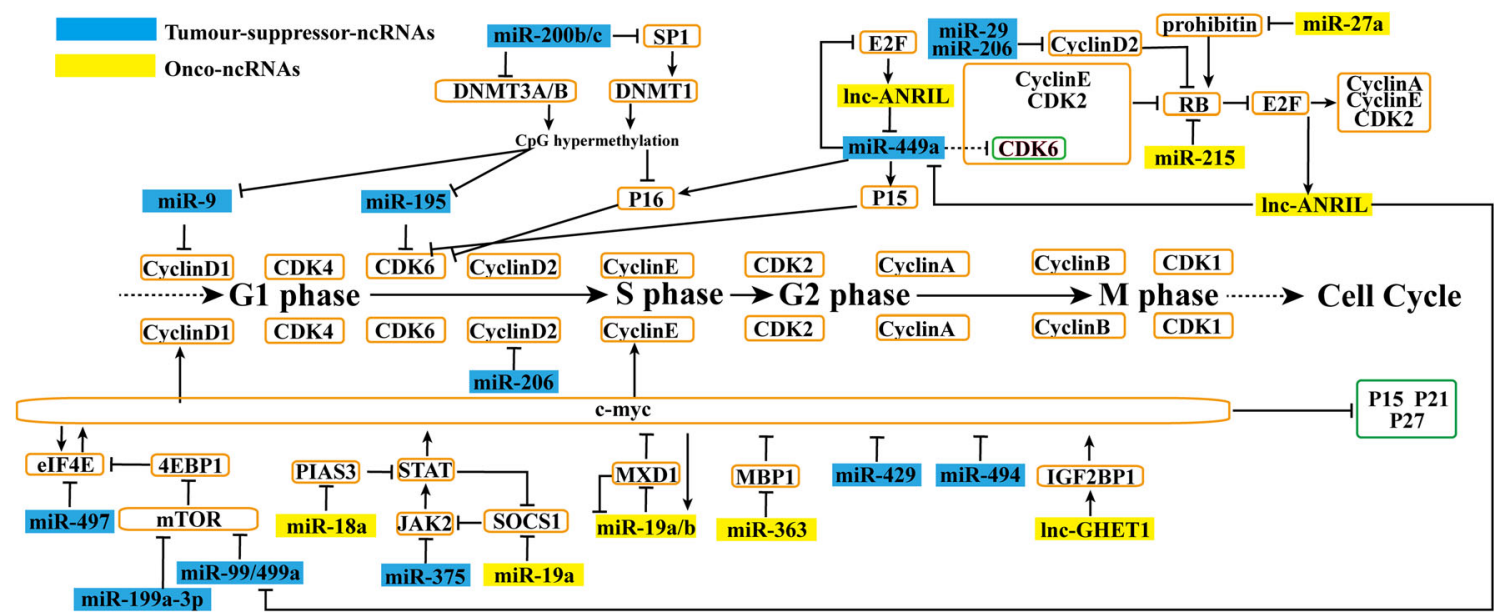

Fig 2 ncRNAs affect CDKIs and Myc pathway in cell cycle. MiRNAs and lncRNAs affect gastric cancer cell cycle progression. By regulating CDKIs and their downstream and

165 [19]. Let-7a decreased in GC regulates the cell cycle by directly downregulating RAB40C, a member of the RAS family [20]. HOTAIR [21] is upregulated in GC and inversely correlates with miR-331-3p. By binding miR-331-3p, HOTAIR acts as a competing endogenous RNA (ceRNA), thus abolishing the miRNA-induced repressive activity on HER2, which promotes GC cell growth through the Akt pathway [22].

\section{Effect downstream of the Akt axis}

As for the downstream of the Akt axis, other miRNAs and lncRNAs can affect FOXO1 or p53 directly or indirectly (Fig. 1). Li et al. suggested that in GC, the NF-KBdependent upregulation of miR-107 could inhibit FOXO1 protein expression and induce proliferation [23]. However, $\mathrm{Li}$ et al. reported the converse result, that miR-107 might act as a tumor suppressor by directly targeting CDK6 to block the GC cell cycle [24]. Different from FOXO1, another member of the FOX family, FOXM1, decreases the activity of $\mathrm{p} 27^{\text {Kip } 1}$. It is negatively regulated by miR-370 and reduced by $\mathrm{Hp}$ infection in GC [25]. Like the FOX family, p53 is influenced by many ncRNAs. Tony et al. found that $\mathrm{Hp}$ indirectly modulated $\mathrm{p} 53$ and its downstream target $\mathrm{p} 21$ by downregulating miR-449 [26]. miR-650 upregulation in GC targets $I N G 4$, which is thought to enhance $\mathrm{p} 53$ function in gene transcription and promote cell growth [27]. miR-181a acts as an oncomir in GC by targeting the tumor suppressor gene ATM [28], which increases the expression and activity of $\mathrm{p} 53$ [29]. TP53INP1 is a key element in p53-mediated cell death and cell cycle arrest. Both miR-17-5p and miR-20a are upregulated in GC and can promote cell growth via deregulating TP53INP1 and P21. However, miR-17-5p/20a function independently on $\mathrm{p} 53$. They also inhibit $\mathrm{p} 21$ indirectly by increasing murine double minute 2 (MDM2), a negative regulator of p21 [30], which is
Myc pathway, onco-ncRNAs promote gastric cancer cell growth. Conversely, tumor suppressor ncRNAs suppress the gastric cancer cell cycle

also promoted by PI3K/Akt signaling in GC [31]. H19 [32] and CCAT1 [33] are c-Myc-induced ncRNAs. Both can decrease the activity of p53 [33, 34]. Furthermore, upregulated H19 promotes miR-675, which inhibits the tumor suppressor runt domain transcription factorl (RUNX1) when promoting GC cell growth [35].

ncRNAs affect CDKIs and their downstream in cell cycle

In addition to the classical Akt pathway, many ncRNAs can directly or indirectly regulate P27, P21, P16, P15 or their downstream targets (Figs. 1 and 2). Sun et al. demonstrated that upregulated miR-196a [36] could inhibit p27 $7^{\text {Kip1 }}$ expression, which prevents cell cycle progression by inhibiting Cyclin E/CDK2 activity. And the suppressive expression of GAS5 resulted in a decrease of P21 and an increase in E2F1 and Cyclin D1 [37] (Fig. 1). miR-212 inhibits proliferation and increases the expression of $\mathrm{P} 21^{\mathrm{Cip} 1}$ and $\mathrm{P} 27^{\mathrm{Kip} 1}$ indirectly by repressing retinoblastoma-binding protein 2 (RBP2) [38] (Fig. 1). Both miR-200b and miR-200c are downregulated in GC and can target DNMT3A/B directly or downregulate DNMT1 indirectly through mediating the decrease of specificity protein 1 (Sp1) (Fig. 2). Decreased DNMTs result in DNA hypomethylation, which is responsible for the overexpression of p16 [39]. Upregulated ANRIL suppresses the expression of miR-449a, p15 $5^{\text {Ink4B }}$, and $\mathrm{p} 16^{\text {Ink } 4 \mathrm{~A}}$. The downregulation of miR-449a releases CDK6. At the same time, the lower expression of $\mathrm{p} 15^{\text {Ink } 4 \mathrm{~B}}$ and $\mathrm{p} 16^{\text {Ink } 4 \mathrm{~A}}$ reduces their inhibitory effect on CDK6 (Fig. 2). Therefore, all this abnormal expression will promote CDK6. Increased CKD6 can inhibit $\mathrm{Rb}$, thus releasing E2F1. In turn, the released E2F1 increases ANRIL expression, forming a positive feedback loop and continuously promoting GC cell proliferation [40]. Complementary to this, both miR-29 [41] and miR-206 [42] act as tumor suppressors by targeting Cyclin D2, which 
regulates the cell cycle by controlling $\mathrm{Rb}$ phosphorylation levels (Fig. 2). In addition, overexpressed miR-215 [43] and miR-27a [44] regulate $\mathrm{Rb}$ directly and indirectly, respectively, via targeting prohibitin genes (Fig. 2). In addition to Cyclin D2, Cyclin D1, which also promotes cell cycle progression by activating CDK4/6, is another important target. Both Sp1 [45] and Sp2 [46] can increase the expression of Cyclin D1. Qiu [45] and Zhao [46] et al. reported that miR-145, miR-133a, and miR-133b could decrease Sp1, and miR-638 could inhibit Sp2. In GC, Sp1 is also regulated by PI3K-Akt signaling [47] (Fig. 1). Furthermore, hypermethylation-mediated silencing of miR-9 [48] directly causes increased Cyclin D1 expression [49]. CDK is also regulated by miRNAs. miR-195 silencing by DNA hypermethylation negatively regulates the expression of CDK6 by binding the CDK6 mRNA 3'-UTR [50] (Fig. 2).

ncRNAs affect the Myc pathway in the cell cycle

Myc is another important functional site in cell cycle. On one hand, it directly induces Cyclin D or Cyclin E expression. On the other hand, it indirectly promotes the cell cycle by inhibiting $\mathrm{p} 15^{\mathrm{INK} 4}, \mathrm{p} 27^{\mathrm{Kip} 1}$, and $\mathrm{p} 21^{\mathrm{CIP} 1}$ [51]. Interestingly, Myc is also regulated by many ncRNAs in GC (Fig. 2). cMyc and eIF4E can promote each other [52]. Meanwhile, eIF4E is increased by mTOR, which phosphorylates 4E-BP1 [53], and inhibited by miR-497 [54]. mTOR is directly inhibited by miR-199a-3p [55] and abrogated by miR-99a/ miR-499a, which are epigenetically inhibited by ANRIL [40]. c-Myc is a STAT3-mediated gene, which is negatively regulated by protein inhibitor of activated signal transducer and activator of transcription 3 (PIAS3). miR-18a indirectly modulates c-Myc by targeting PIAS3 [56]. Suppressors of cytokine signaling (SOCS) family proteins are important negative feedback inhibitors of JAK/STAT [57]. miR-375 [58] can repress JAK2, and miR-19a [57] can downregulate SOCS1. Therefore, all three miRNAs may ultimately affect the GC cell cycle through regulating c-Myc. c-Myc also acts as a transactivator of miR-19a/b, which inhibits MXD1 expression. In turn, downregulated MXD1 loses its inhibitory effect on miR-19a/b and c-Myc. The direct association between miR-19a/b and the c-Myc antagonist gene MXD1 indicates a positive feedback loop between the three [59]. Upregulated miR-363 promotes GC cell growth by suppressing c-Myc promoter binding protein 1 (MBP-1), which initiates the specific inactivation of Myc [60]. In addition to these indirect effects, some miRNAs regulate c-Myc directly in GC. Both the downregulation of miR-429 [61] and miR-494 [62] cause increased c-Myc. In addition to miRNAs, GHET1 promotes the stability and expression of c-Myc by interacting with insulin-like growth factor 2 mRNA binding protein 1 (IGF2BP1) [63].

\section{ncRNAs associated with apoptosis in GC}

Apoptosis is an intrinsic cellular suicide program. Its initiation and progress are accurately regulated by upstream regulators and downstream effectors. Caspases are generally categorized as initiators (caspase-2, -8, -9, -10) and effectors (caspase-3, $6,-7)$. These initiators activate apoptosis through the following three signaling pathways: (1) the death receptor pathway (extrinsic pathway), (1) the mitochondrion pathway (intrinsic pathway), and (3) the endoplasmic reticulum pathway [64, 65]. The extrinsic apoptotic program contains the Fas ligand/ Fas receptor and Apo3. For example, the Fas-associated death domain protein (FADD) directly binds to the Fas death domain and activates caspase- 8 , leading to cell death [65]. For the intrinsic pathway, the regulators and effectors are controlled by counterbalancing the Bcl-2 family, including the proapoptotic (Bax, Bak, Bok, Bim, Bid, Bad, Bmf, Bik, BNIP3L, Noxa, Puma, and Hark) and antiapoptotic (Bcl-2, Bcl-xL, Bcl-w, Mcl-1, and Al/Bfl-1) members [2]. These dysregulated apoptotic molecules can change the permeability of the mitochondrial membrane and the release of cytochrome $\mathrm{C}$ (Cyt c) and other proteins. Cyt c can raise the intracellular quality of caspase-9 precursors and promote self-activation, starting a caspase cascade and activating downstream caspase- 3 and caspase-7, which cause apoptosis. All these pathways associate with each other and coordinately regulate apoptosis [65] (Fig. 3).

ncRNAs affect apoptosis initiators

Altered expression of miRNAs can affect the progress of apoptosis in GC cells [2, 6]. (Fig. 3). First, we discuss how miRNAs influence cell apoptosis by affecting apoptosis initiators. In GC, many miRNAs directly modulate Bcl-2 expression. Downregulation of miR-15b, miR-16, miR-34, miR$181 b$ [2], miR-204 [66], and miR-449a [67] promotes GC cell apoptosis by negatively regulating $\mathrm{Bcl}-2$. Bcl-2 is also indirectly regulated by miRNAs. The downregulation of PTEN promotes the Akt signaling pathway, resulting in increased NF-kB. Furthermore, activated NF-kB upregulates the expression of Cox-2 [13], which reduces apoptosis by promoting $\mathrm{Bcl}-2$ expression [68]. Interestingly, this chain reaction is observed in GC cells and is regulated by specific miRNAs. First, upregulated miR-21 [12] and miR-221/222 [2] can target PTEN directly. Meanwhile, NF-KB can induce miR-21 expression [15], thus forming a positive feedback loop between miR-21 and NF-kB. Second, the upregulation of miR-362 increases the activity and expression of NF- $\mathrm{KB}$ through inhibiting CYLD expression [16]. miR-218, which is reduced by $\mathrm{Hp}$ infection, inhibits NF-KB indirectly by targeting epidermal growth factor receptor-coamplified and overexpressed protein (ECOP) [69]. Finally, miR-101, which is decreased in GC, binds to the 3'-UTR of Cox-2 mRNA, and inhibits Cox-2 


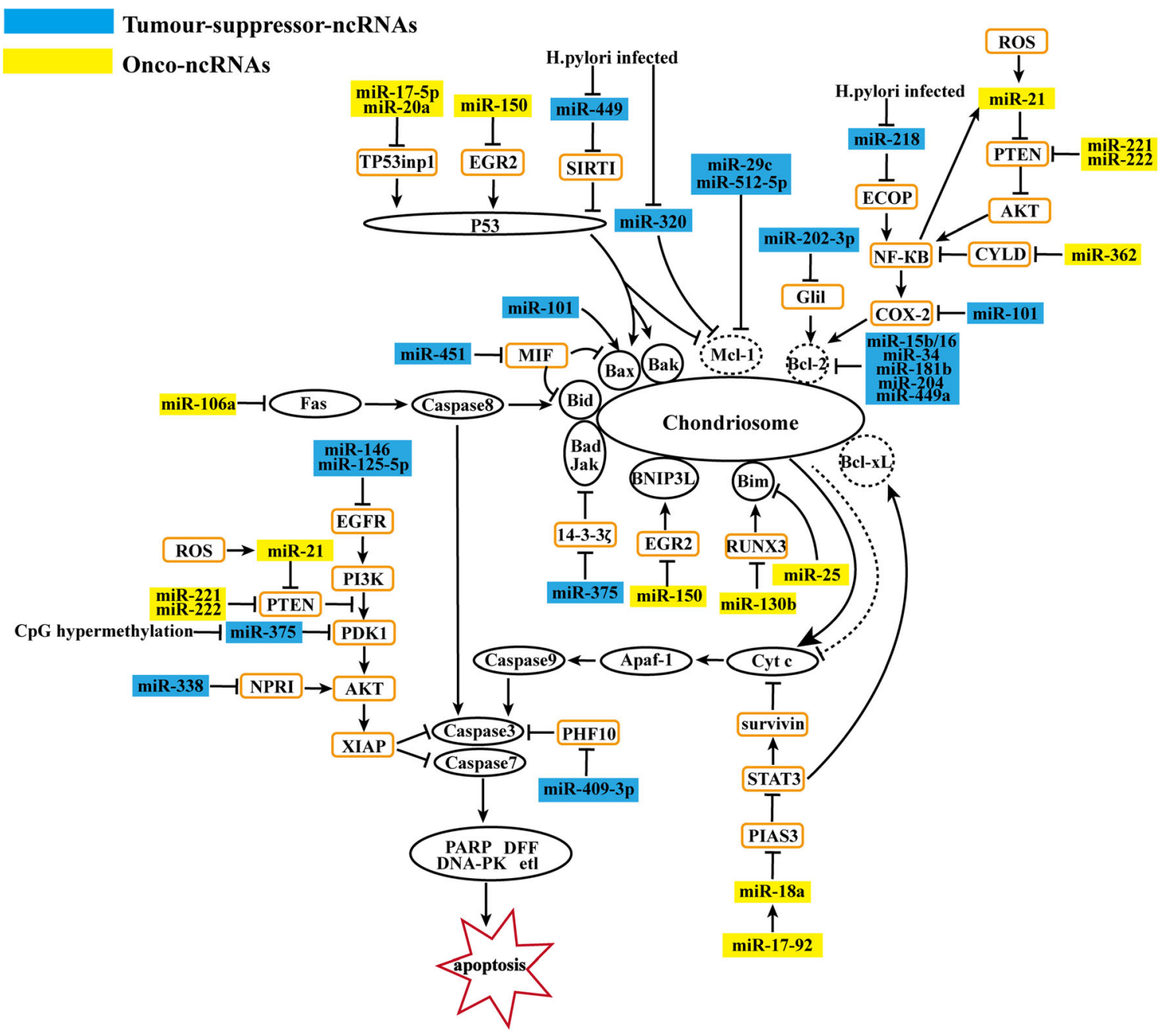

Fig 3 ncRNAs associated with apoptosis in GC. MiRNAs and lncRNAs affect gastric cancer cell apoptosis. By regulating extrinsic and intrinsic pathways, onco-ncRNAs suppress gastric cancer apoptosis. Conversely, tumor suppressor ncRNAs promote gastric cancer cell apoptosis

expression directly [68]. In addition, miR-202-3p downregulation in $\mathrm{GC}$ can reduce Bcl-2 by inhibiting Gli1 [70]. Other $\mathrm{Bcl}-2$ family members, such as Bax and Bid, are also regulated by miRNAs in GC. The transcription factor $\mathrm{p} 53$, which localizes in the mitochondria, can interact with Bak and Bax directly. However, this interaction blocks the interaction of Bak and Mcl-1. These effects change the mitochondrial permeability, resulting in the release of apoptosis factors and eventually leading to apoptosis [65]. In GC, many miRNAs can control cell apoptosis by regulating p53 and its downstream molecules. Upregulated miR-17-5p/20a decreases the expression of TP53INP1, thus weakening the role of p53 [30]. miR-449 reduction by $\mathrm{Hp}$ in GC induces apoptosis by inhibiting SIRT1, which represses the p53 pathway [26]. Upregulated miR-23a [71] directly targets IRF1, which mediates apoptosis by upregulating the expression of $\mathrm{p} 53$ upregulated modulator of apoptosis (PUMA). However, this is p53 independent [64]. miR-150 promotes GC cell proliferation by inhibiting EGR2, which enhances p53-mediated apoptosis and activates the proapoptotic proteins BNIP3L and Bak [2]. In addition, downregulated miR-101 promotes Bax expression directly [68], and miR-451 increases Bid- and Baxmediated apoptosis by targeting macrophage migration inhibitory factor (MIF) [2]. Similarly, upregulated miR-25 and miR-130b inhibit the expression of Bim directly and indirectly, respectively, through decreasing RUNX3 [2]. Downregulated miR-29c [72], miR-512-5p [2], and miR-320 [73], which is inhibited by Hp, can suppress the expression of Mcl-1. In addition to this intrinsic pathway, miR-106a upregulated in GC represses the extrinsic pathway by targeting the 3'-UTR of Fas directly [74].

ncRNAs affects apoptosis effectors

Next, we discuss the influence of miRNAs on apoptosis effectors (Fig. 3). By DNA methylation, miR-375 silencing in $\mathrm{GC}$ can induce apoptosis in two ways. First, miR-375 can inhibit the PDK1/Akt/XIAP pathway. Downstream of Akt, 
XIAP inhibits apoptosis by suppressing caspase activity. Second, miR-375 targets the $3^{\prime}$ UTR of 14-3-3 , which inhibits proapoptotic proteins such as Bad and JAK. Both siPDK1 and si14-3-3 $\zeta$ transfectants increased caspase-3/7 activity [75]. In addition to miR-375, many other miRNAs can also affect apoptosis through the Akt pathway. miR-125-5p and miR-146a are downregulated in GC, and both regulate Akt by directly targeting the EGFR mRNA [2]. As mentioned above, PTEN is a negative regulator of PI3K-Akt signaling. The miR-221/222 cluster [2] and miR-21 [12] block apoptosis of GC cells by targeting PTEN mRNA directly. miR-338 promotes apoptosis and regulates the phosphorylation of Akt by inhibiting neuropilin-1 (NRP1) [19]. Beyond these classic indirect ways, caspase-3, a direct effector of apoptosis, is also activated by miRNAs. The downregulation of miR-409-3p results in the overexpression of PHF 10 in GC. PHF10 inhibits cell apoptosis by binding to the promoter region of caspase-3 directly [76]. The miR-17-92 cluster encodes miR-18a, which can promote STAT3 and its downstream effectors including Myc, survivin, and Bcl-xl through inhibiting PIAS3, which negatively regulates STAT3. Bcl-xl is anti-apoptotic, and survivin inhibits the release of Cyt $\mathrm{c}$ and the level of caspase-3 [77]. Therefore, miR-18a may block the apoptotic process [56].

Interestingly, unlike miRNAs, HULC upregulation in GC tissues and cell lines inhibits cell apoptosis by activating autophagy, which has a dual role in cancer development [78].

\section{ncRNAs associated with invasion and metastasis in GC}

Tumor invasion and metastasis are complex and multistep processes. Here, we discuss three aspects: (1) the alteration of cell phenotypes including the decrease of epithelial cell marker genes such as E-cadherin, the increase of mesenchymal cell marker genes such as $\mathrm{N}$-cadherin and integrin [79], and changes in tumor cell motility and shape [80] - these conversions are also called epithelial-mesenchymal transition (EMT); (2) the remodeling of the extracellular matrix (ECM), which requires matrix metalloproteinases (MMPs) and other proteolytic enzymes [2], and (3) the proliferation of neovascularization, which contributes to an invasive and metastatic tumor microenvironment [79].

EMT is induced by several signaling pathways. Transforming growth factor beta (TGF $\beta$ ) is the most potent and most well-described inducer. Others like E-cadherin transcriptional repressors also act as EMT inducers, including the Snail, zebra (ZEB), and Twist families [81]. TGF $\beta 1$ initiates EMT by activating either the Smad 2/3/4 trimer or non-Smad pathways, including PI3K/Akt, RAS small GTPases, and Wnt $/ \beta$-catenin. Many of these pathways work synergistically in EMT. For instance, TGF $\beta$-mediated Smad3/4 promote Snail and ZEB1/2 expression [80], and the activation of GF/
TGF $\beta$-Ras-Akt signaling increases the expression of Snail, Twist, Slug, and Smad [17]. The stimulation of myosin light chain phosphorylation and actin reorganization can potentiate TGF $\beta$-induced EMT. $\beta$-catenin signaling, which is enhanced by TGF $\beta$ [80] and inhibited by Akt [17], can mediate the binding of E-cadherin to the actin cytoskeleton and regulate the expression of Snail and Slug [80]. It is noteworthy that $\mathrm{NF}-\mathrm{kB}$ has been identified as a key regulator of EMT as it can induce the expression of Snail and ZEB1/2. In addition, EMT is regulated by cytokines and integrin signaling [80].

There is no doubt that the mechanisms of tumor invasion and metastasis are complex. Interestingly, both miRNAs [82] and $\operatorname{lncRNAs}[5]$ participate in cancer metastasis in $\mathrm{GC}[2,6]$.

ncRNAs associated with EMT in GC

\section{Effect of miRNAs and lncRNAs on signaling upstream of EMT}

The GF-Ras-PI3K-Akt pathway plays a key role in EMT [17]. In GC, many miRNAs regulate EMT by affecting GFs or their receptors and Akt signaling (Fig. 4). miR-146a [83] and miR7 [84] suppress EGFR. Meanwhile, miR-7 is inversely correlated with insulin-like growth factor-1 receptor (IGF1R) [85]. miR-26a attenuates FGF9 [86], miR-34a inhibits PDGFR-a/b [87], and miR-338 decreases NRP1, a receptor for the vascular endothelial growth factor (VEGF) [19]. All five miRNAs are downregulated in GC and can inhibit cell migration. TGF $\beta$ not only activates the Ras-PI3K-Akt pathway [17] but also promotes EMT by regulating Smad2/3 [80]. Surprisingly, S$\mathrm{S}$ Lo et al. reported that miR-370 increased the migration of GC cells by disrupting TGF $\beta$ signaling [88]. However, TGF $\beta$ is not the only way to regulate Smads. miR-155, which is downregulated by DNA methylation, may inhibit Smad2 expression by targeting its 3'UTR [89]. In addition, ROS promotes the expression of miR-21 in GC [14]. In turn, upregulated miR-21 inhibits PTEN [12], reducing its inhibitory effect on Akt [17]. Furthermore, Cox-2 stimulated by nicotine can promote miR-21 expression via activating NF- $\mathrm{kB}$, which targets miR-21 directly [15]. Thus, a complex network forms among NF-kB, Akt, and EMT by regulating miRNAs.

NF-kB not only targets miRNAs but is also regulated by many miRNAs in GC (Fig. 4). As an oncomir, miR-363 [60] enhances EMT through inhibiting MBP-1, which blocks Cox2 expression. Consistently, the upregulation of Cox-2 activates NF-KB/Snail signaling but decreases E-cadherin expression [90]. The reduction of miR-146a is associated with the upregulation of EGFR and IRAK1. IRAK1 is upstream of NF- $\mathrm{KB}$, and EGFR activates NF- $\mathrm{KB}$ by attenuating I $\mathrm{KB}$ [83]. miR-1228* is downregulated and forms a negative feedback loop with NF-KB through targeting CK2A2 expression, which degrades IKB [91]. DNA hypermethylation can result in low miR-9 expression in GC. Dysregulated miR-9 affects cell metastasis in two ways. First, it inhibits NF-KB1. Second, 


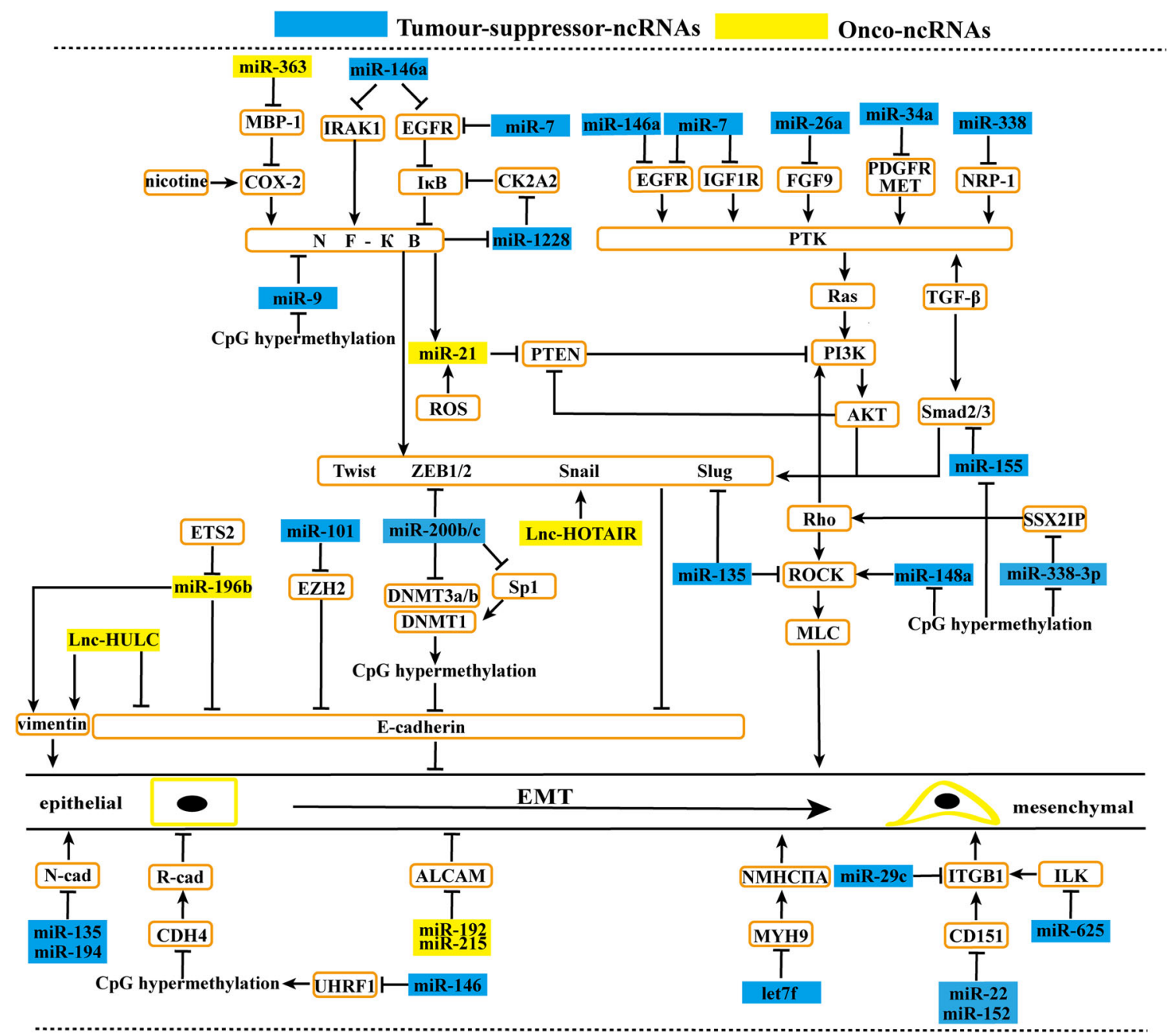

Fig 4 ncRNAs associated with EMT in GC. MiRNAs and lncRNAs affect gastric cancer cell metastasis. By regulating EMT, onco-ncRNAs promote gastric cancer cell metastasis. Conversely, tumor suppressor ncRNAs suppress gastric cancer cell metastasis

it decreases the expression of MMP2, MMP9, Twist, and N-cadherin [48].

\section{Direct effects of miRNAs and lncRNAs on EMT-TFs or the phenotype of GC cells}

In addition to affecting the signaling upstream of EMT, a host of miRNAs and lncRNAs can also directly regulate the EMTTFs or the phenotype of GC cells (Fig. 4). miR-101, which is downregulated in GC, increases the expression of E-cadherin through inhibiting EZH2 [92]. In GC, lack of ETS2 causes the upregulation of miR-196b, which increases the expression of vimentin, MMP2, and MMP9, but decreases E-cadherin [93]. The miR-200 family, including miR-200a/b/c, is downregulated in GC. During EMT, they not only negatively regulate ZEB1/2 [94] but also inhibit DNA methyltransferases (DNMTs), leading to the hypomethylation of promoter DNA and upregulation of E-cadherin [39]. Furthermore, miR-135a downregulation in GC can increase E-cadherin expression by suppressing Slug expression and inhibiting N-cadherin expression [95]. Song et al. reported that with the transfection of miR-194 mimics, both the expression of N-cadherin and the metastasis of GC cells were suppressed [96]. miR-146a/b downregulation in $\mathrm{GC}$ can regulate metastasis by reducing the expression of epigenetic regulator ubiquitin-like containing PHD ring finger 1 (UHRF1), which maintains DNA methylation by recruiting DNMT1. DNA hypermethylation can silence $\mathrm{CDH} 4$ and $\mathrm{RUNX} 3$. CDH4 encodes R-cadherin, and Runx3 inhibits MMP9 via upregulating TIMP-1 [97]. Both miR-192 and miR-215 are upregulated in GC and can significantly decrease the expression of ALCAM, a cell adhesion molecule expressed by epithelial cells [98]. Like miRNAs, lncRNAs play important roles in EMT. HULC is overexpressed in GC, and knockdown of HULC can downregulate vimentin and upregulate E-cadherin expression [78]. In addition, HOTAIR, which is also upregulated in GC, promotes EMT by stimulating the expression of Snail, MMP1, and MMP3 [99]. 


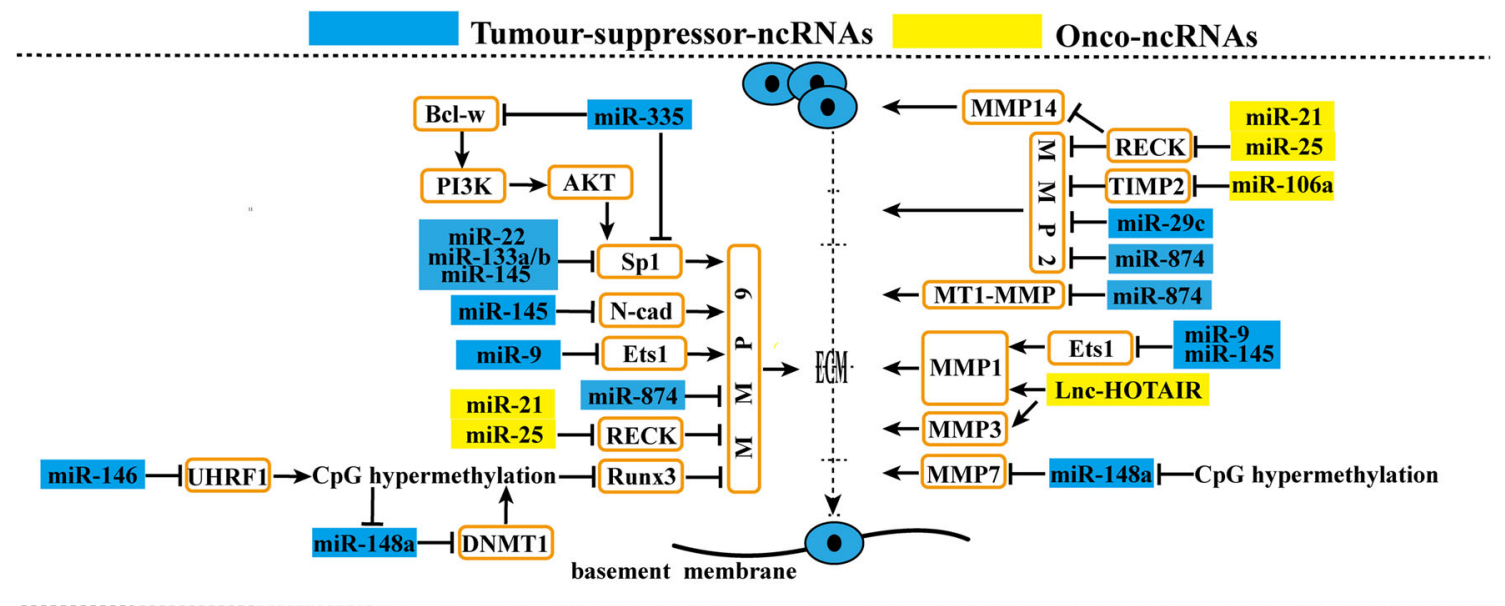

Fig 5 Degradation of ECM by ncRNAs in GC. MiRNAs and lncRNAs affect gastric cancer cell metastasis. By regulating remodeling of ECM, onconcRNAs promote gastric cancer cell metastasis. Conversely, tumor suppressor ncRNAs suppress gastric cancer cell metastasis

\section{Effect of miRNAs and IncRNAs on cancer cell motility}

During EMT, cancer cell motility also changes greatly and is regulated by many ncRNAs (Fig. 4). Accumulating evidence has reported that Rho [100] promotes cell invasion by regulating the PI3K/Akt and ROCK signaling pathways, which promote actomyosin contractility via mediating the phosphorylation of MLC, significantly contributing to cell motility $[101,102]$. Epigenetically silenced miR-338-3p can inhibit the expression of Rac1, a Rho family member, by reducing SSX2IP expression [103]. Both downregulated miR-135 [95] and miR-148a [102], which is silenced by DNA hypermethylation [104], target ROCK1 directly. PINCH, integrin-linked kinase (ILK) and parvin work as a PINCH-ILK-parvin (PIP) complex. PIP complexes provide crucial physical linkages between integrins and the actin cytoskeleton and transduce signaling from the ECM to intracellular effectors. ILK contains many distinct integrin binding sites. It is therefore assumed that an integrin $\beta$-IPP-actin pathway is involved in abnormal cell-ECM adhesion and cell motility [105]. In GC, downregulated miR-625 [106] and miR-29c [107] can target ILK and integrin $\beta$, respectively. However, miR-22 [108] and miR-152 [109] suppress GC cell motility partially by inhibiting CD151, which contributes to integrin-mediated metastasis. Let-7f inhibits and binds to the 3'-UTR of MYH9, which codes for myosin IIA directly, leading to an attenuation of cell motility [110].

\section{Degradation of ECM by ncRNAs}

The degradation of the ECM is a crucial step in the progression of tumor metastasis. MMPs hydrolyze type IV collagen and promote cell invasion [111]. Similarly, MMPs are also inhibited or activated by many signaling molecules and ncRNAs (Fig. 5). Bcl-w promotes GC metastasis by activating the PI3K-Akt-Sp1 pathway. miR-335, which is downregulated in $\mathrm{GC}$, prevents cell invasion and metastasis by targeting specificity protein 1 (Sp1) directly, and indirectly through regulating Bcl-w [47]. miR-22, miR-133a, miR-133b, and miR-145 are also downregulated in $\mathrm{GC}$ and can inhibit metastasis via negatively regulating $\mathrm{Sp} 1[45,112]$. Meanwhile, Qiu et al. reported that in GC, knockdown of Sp1 reduced the expression of MMP-9 [45]. MMP-9 may therefore be the common effector of the five miRNAs. N-cadherin also acts as an upstream promoter of $M M P 9$ and is directly inhibited by miR-145, which is downregulated in GC [113]. In addition, both $M M P 1$ and $M M P 9$ are downstream of v-ets erythroblastosis virus E26 oncogene homolog 1 (Ets1), and Ets1 is suppressed by miR-145
Fig 6 Angiogenesis by ncRNAs in GC. MiRNAs and lncRNAs affect gastric cancer cell metastasis. By regulating angiogenesis, onco-ncRNAs promote gastric cancer cell metastasis. Conversely, tumor suppressor ncRNAs suppress gastric cancer cell metastasis

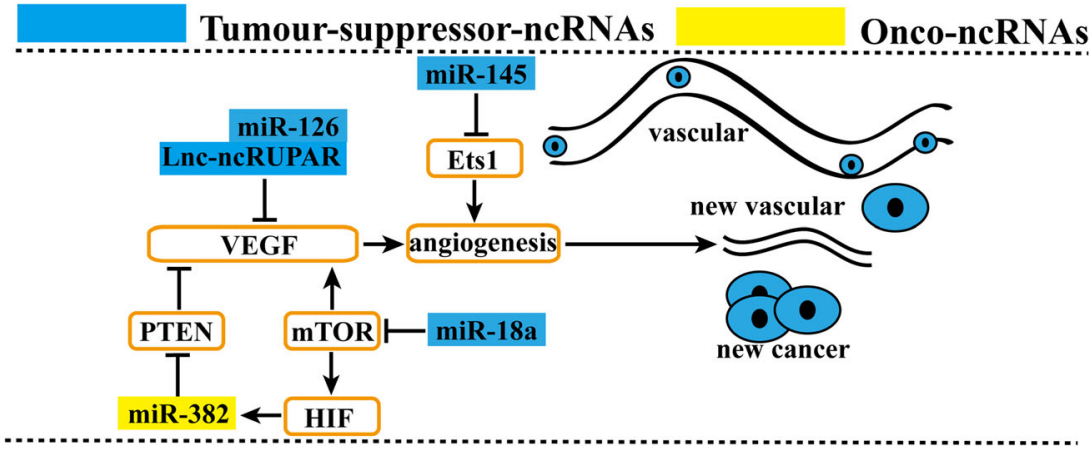


[114] and miR-9 [48, 49] downregulation in GC. As a member of the tissue inhibitors of metalloproteinases (TIMPs) family, TIMP2 can combine with MMP2 directly and work as downstream of miR-106a, which is upregulated in GC [115]. However, miR-21 [2] and miR-25 [116], which are also elevated in GC, can suppress reversion-inducing cysteine-rich protein with kazal motifs (RECK), a new MMP inhibitor, which simultaneously inhibits MMP-2, MMP-9, and MMP14. miR-874 can suppress MT1-MMP, MMP-2, and MMP-9, and these inhibitory effects may be dependent upon AQP3 [117]. In addition to these indirect effects, many miRNAs and IncRNAs act as direct regulators of MMPs in GC. For example, miR-29 targets MMP2 [41], and miR-148a targets MMP7 [118]. Furthermore, upregulated HOTAIR can induce the expression of MMP1 and MMP3 [99].

\section{Angiogenesis by ncRNAs}

Tumor-associated endothelial cells, composing the arteries, veins, and capillaries, are prominent tumor stromal constituents and play key roles in cell metastasis [79]. Although the impact is not so great as on EMT, some ncRNAs affect the development of tumor-associated angiogenesis (Fig. 6). miR126, which was downregulated, facilitated GC angiogenesis by regulating VEGF-A [119]. miR-382 was induced by hypoxia, promoted angiogenesis, and acted as an angiogenic oncogene by repressing PTEN, which inhibited miR-382induced angiogenesis and VEGF secretion [120]. miR-18a overexpression significantly reduced tumor angiogenesis and substantially reduced the inactivation of the mTOR pathway. Accompanying mTOR inactivation, the angiogenic factors hypoxia-inducible factor 1 alpha and vascular endothelial growth factor were significantly downregulated [121]. miR145 was downregulated and suppressed Ets 1 expression via the binding site in the $3^{\prime}$-UTR, thus inhibiting the invasion, metastasis, and angiogenesis of gastric cancer cells [114]. RuPAR is reduced and inversely associated with the expression of VEGF protein in GC tissues. Moreover, both are significantly correlated with invasion depth, lymph node metastasis, and distant metastasis [122]. Therefore, we speculated that ruPAR promotes GC metastasis by stimulating angiogenesis.

\section{Conclusion}

The molecular mechanisms of miRNAs and lncRNAs in gastric carcinogenesis are much more complex than we discussed in this paper. Functional analyses have shown that these miRNAs and lncRNAs interact with mRNAs from oncogenes and tumor suppressor genes. The altered expression of ncRNAs in GC promotes cell cycle progression via direct and indirect regulation of Akt pathways, CDKIs or Myc, reduces apoptotic signaling through the regulation of apoptosis initiators and apoptosis effectors, and promotes cell migration and invasion by regulating EMT pathways, degradation of ECM by ncRNAs or angiogenesis. They work in a network rather than as individuals. One ncRNA can affect several biological behaviors, including the cell cycle, apoptosis, and metastasis, through several signaling pathways. Meanwhile, one signaling pathway can be affected by several ncRNAs and can regulate several biological behaviors. Therefore, blocking only one of these functional sites or ncRNAs may not stop the progress of gastric tumorigenesis. These novel mechanisms of miRNA and lncRNAs not only help us elucidate the pathogenesis of GC, but also offer us opportunities for ncRNAtargeting strategies. However, the great complexity of these mechanisms also brings a huge challenge to the study of ncRNAs in GC.

\section{Conflicts of interest None}

Open Access This article is distributed under the terms of the Creative Commons Attribution License which permits any use, distribution, and reproduction in any medium, provided the original author(s) and the source are credited.

\section{References}

1. Piazuelo MB, Correa P. Gastric cancer: overview. Colomb Med (Cali, Colombia). 2013;44:192-201.

2. Song JH, Meltzer SJ. MicroRNAs in pathogenesis, diagnosis, and treatment of gastroesophageal cancers. Gastroenterology. 2012;143: $35-47$ e32.

3. Esteller M. Non-coding RNAs in human disease. Nat Rev Genet. 2011;12:861-74.

4. Wu HH, Lin WC, Tsai KW. Advances in molecular biomarkers for gastric cancer: MiRNAs as emerging novel cancer markers. Expert Rev Mol Med. 2014;16:e1.

5. Li X, Wu Z, Fu X, Han W. Long non-coding RNAs: insights from biological features and functions to diseases. Med Res Rev. 2013;33:517-53.

6. Li P-F. Non-coding RNAs and gastric cancer. World J Gastroenterol. 2014;20:5411.

7. Noatynska A, Tavernier N, Gotta M, Pintard L. Coordinating cell polarity and cell cycle progression: what can we learn from flies and worms? Open Biol. 2013;3:130083.

8. Hindley C, Philpott A. The cell cycle and pluripotency. Biochem J. 2013;451:135-43.

9. Kapinas K, Grandy R, Ghule P, Medina R, Becker K, Pardee A, et al. The abbreviated pluripotent cell cycle. J Cell Physiol. 2013;228:9-20.

10. Xia J, Wu Z, Yu C, He W, Zheng H, He Y, et al. Mir-124 inhibits cell proliferation in gastric cancer through down-regulation of SPHK1. J Pathol. 2012;227:470-80.

11. Guo SL, Ye H, Teng Y, Wang YL, Yang G, Li XB, et al. Akt-p53miR-365-Cyclin D1/cdc25A axis contributes to gastric tumorigenesis induced by PTEN deficiency. Nat Commun. 2013;4:2544.

12. Zhang BG, Li JF, Yu BQ, Zhu ZG, Liu BY, Yan M. MicroRNA-21 promotes tumor proliferation and invasion in gastric cancer by targeting PTEN. Oncol Rep. 2012;27:1019-26. 
13. Namba H, Saenko V, Yamashita S. Nuclear factor-kB in thyroid carcinogenesis and progression: a novel therapeutic target for advanced thyroid cancer. Arq Bras Endocrinol Metabologia. 2007;51: $843-51$.

14. Tu H, Sun H, Lin Y, Ding J, Nan K, Li Z, et al. Oxidative stress upregulates PDCD4 expression in patients with gastric cancer via miR-21. Curr Pharm Des. 2014;20:1917-23.

15. Shin VY, Jin H, Ng EK, Cheng AS, Chong WW, Wong CY, et al. NF- $\mathrm{kB}$ targets miR-16 and miR-21 in gastric cancer: involvement of prostaglandin e receptors. Carcinogenesis. 2011;32:240-5.

16. Xia JT, Chen LZ, Jian WH, Wang KB, Yang YZ, He WL, et al. MicroRNA-362 induces cell proliferation and apoptosis resistance in gastric cancer by activation of NF- $\mathrm{kB}$ signaling. J Transl Med. 2014;12:33.

17. Sheng S, Qiao M, Pardee AB. Metastasis and Akt activation. J Cell Physiol. 2009;218:451-4.

18. Nishida N, Mimori K, Fabbri M, Yokobori T, Sudo T, Tanaka F, et al. MicroRNA-125a-5p is an independent prognostic factor in gastric cancer and inhibits the proliferation of human gastric cancer cells in combination with trastuzumab. Clin Cancer Res Off J Am Assoc Cancer Res. 2011;17:2725-33.

19. Peng Y, Liu YM, Li LC, Wang LL, Wu XL. MicroRNA-338 inhibits growth, invasion and metastasis of gastric cancer by targeting NRP1 expression. PLoS ONE. 2014;9:e94422.

20. Yang Q, Jie Z, Cao H, Greenlee AR, Yang C, Zou F, et al. Low-level expression of let-7a in gastric cancer and its involvement in tumorigenesis by targeting RAB40C. Carcinogenesis. 2011;32:713-22.

21. Liu XH, Sun M, Nie FQ, Ge YB, Zhang EB, Yin DD, et al. Lnc RNA HOTAIR functions as a competing endogenous RNA to regulate HER2 expression by sponging miR-331-3p in gastric cancer. Mol Cancer. 2014;13:92.

22. Sukawa Y, Yamamoto H, Nosho K, Ito M, Igarashi H, Naito T, et al. HER2 expression and PI3K-Akt pathway alterations in gastric cancer. Digestion. 2014;89:12-7.

23. Li F, Liu B, Gao Y, Liu Y, Xu Y, Tong W, et al. Upregulation of microRNA-107 induces proliferation in human gastric cancer cells by targeting the transcription factor FOXO1. FEBS Lett. 2014;588: 538-44.

24. Feng L, Xie Y, Zhang H, Wu Y. miR-107 targets Cyclin-dependent kinase 6 expression, induces cell cycle G1 arrest and inhibits invasion in gastric cancer cells. Med Oncol. 2012;29:856-63.

25. Feng Y, Wang L, Zeng J, Shen L, Liang X, Yu H, et al. FoxM1 is overexpressed in helicobacter pylori-induced gastric carcinogenesis and is negatively regulated by miR-370. Mol Cancer Res MCR. 2013;11:834-44.

26. Bou Kheir T, Futoma-Kazmierczak E, Jacobsen A, Krogh A, Bardram L, Hother C, et al. Mir-449 inhibits cell proliferation and is down-regulated in gastric cancer. Mol Cancer. 2011;10:29.

27. Zhang X, Zhu W, Zhang J, Huo S, Zhou L, Gu Z, et al. MicroRNA650 targets ING4 to promote gastric cancer tumorigenicity. Biochem Biophys Res Commun. 2010;395:275-80.

28. Zhang X, Nie Y, Li X, Wu G, Huang Q, Cao J, Du Y, Li J, Deng R, Huang D, Chen B, Li S, Wei B: Microrna-181a functions as an oncomir in gastric cancer by targeting the tumour suppressor gene atm. Pathology oncology research : POR 2014.

29. Kubota E, Williamson CT, Ye R, Elegbede A, Peterson L, LeesMiller SP, et al. Low ATM protein expression and depletion of $\mathrm{p} 53$ correlates with olaparib sensitivity in gastric cancer cell lines. Cell Cycle (Georgetown, Tex). 2014;13:2129-37.

30. Wang M, Gu H, Qian H, Zhu W, Zhao C, Zhang X, et al. miR-17$5 \mathrm{p} / 20 \mathrm{a}$ are important markers for gastric cancer and murine double minute 2 participates in their functional regulation. Eur J Cancer. 2013;49:2010-21.

31. Ai YW, Yu HG, Yu JP, Yang Y, Li H, Hu XW, et al. [Impact of PI3K/ Akt $/ \mathrm{mdm} 2$ signaling pathway on the sensitivity of gastric cancer cell line SGC7901 to doxorubicin] [Article in Chinese]. Zhonghua Zhong Liu Za Zhi [Chin J Oncol]. 2008;30:494-97.

32. Zhang EB, Han L, Yin DD, Kong R, De W, Chen J. C-Myc-induced, long, noncoding $\mathrm{H} 19$ affects cell proliferation and predicts a poor prognosis in patients with gastric cancer. Med Oncol. 2014;31:914

33. Yang F, Xue X, Bi J, Zheng L, Zhi K, Gu Y, et al. Long noncoding RNA CCAT1, which could be activated by c-Myc, promotes the progression of gastric carcinoma. J Cancer Res Clin Oncol. 2013; 139:437-45.

34. Yang F, Bi J, Xue X, Zheng L, Zhi K, Hua J, et al. Up-regulated long non-coding RNA H19 contributes to proliferation of gastric cancer cells. FEBS J. 2012;279:3159-65.

35. Zhuang M, Gao W, Xu J, Wang P, Shu Y. The long non-coding RNA H19-derived miR-675 modulates human gastric cancer cell proliferation by targeting tumor suppressor RUNX1. Biochem Biophys Res Commun. 2014;448:315-22.

36. Sun M, Liu XH, Li JH, Yang JS, Zhang EB, Yin DD, et al. miR196a is upregulated in gastric cancer and promotes cell proliferation by downregulating p27(kip1). Mol Cancer Ther. 2012;11:842-52.

37. Sun M, Jin FY, Xia R, Kong R, Li JH, Xu TP, et al. Decreased expression of long noncoding RNA GAS5 indicates a poor prognosis and promotes cell proliferation in gastric cancer. BMC Cancer. 2014;14:319.

38. Jiping Z, Ming F, Lixiang W, Xiuming L, Yuqun S, Han Y, et al. MicroRNA-212 inhibits proliferation of gastric cancer by directly repressing retinoblastoma binding protein 2. J Cell Biochem. 2013;114:2666-72.

39. Tang H, Deng M, Tang Y, Xie X, Guo J, Kong Y, et al. miR-200b and miR-200c as prognostic factors and mediators of gastric cancer cell progression. Clin Cancer Res Offl J Am Assoc Cancer Res. 2013;19:5602-12.

40. Zhang EB, Kong R, Yin DD, You LH, Sun M, Han L, et al. Long noncoding RNA ANRIL indicates a poor prognosis of gastric cancer and promotes tumor growth by epigenetically silencing of miR99a/miR-449a. Oncotarget. 2014;5:2276-92.

41. Gong J, Li J, Wang Y, Liu C, Jia H, Jiang C, et al. Characterization of microRNA-29 family expression and investigation of their mechanistic roles in gastric cancer. Carcinogenesis. 2014;35:497-506.

42. Zhang L, Liu X, Jin H, Guo X, Xia L, Chen Z, et al. miR-206 inhibits gastric cancer proliferation in part by repressing Cyclin D2. Cancer Lett. 2013;332:94-101.

43. Deng Y, Huang Z, Xu Y, Jin J, Zhuo W, Zhang C, et al. miR-215 modulates gastric cancer cell proliferation by targeting RB1. Cancer Lett. 2014;342:27-35.

44. Liu T, Tang H, Lang Y, Liu M, Li X. MicroRNA-27a functions as an oncogene in gastric adenocarcinoma by targeting prohibitin. Cancer Lett. 2009;273:233-42.

45. Qiu T, Zhou X, Wang J, Du Y, Xu J, Huang Z, et al. miR-145, miR$133 \mathrm{~A}$ and miR-133b inhibit proliferation, migration, invasion and cell cycle progression via targeting transcription factor $\mathrm{Sp} 1$ in gastric cancer. FEBS Lett. 2014;588:1168-77.

46. Zhao LY, Yao Y, Han J, Yang J, Wang XF, Tong DD, et al. miR-638 suppresses cell proliferation in gastric cancer by targeting Sp2. Dig Dis Sci. 2014;59:1743-53.

47. Xu Y, Zhao F, Wang Z, Song Y, Luo Y, Zhang X, et al. MicroRNA335 acts as a metastasis suppressor in gastric cancer by targeting Bcl-w and specificity protein 1. Oncogene. 2012;31:1398-407.

48. Tsai KW, Liao YL, Wu CW, Hu LY, Li SC, Chan WC, et al. Aberrant hypermethylation of miR-9 genes in gastric cancer. Epigenetics: Off J DNA Methylation. 2011;6:1189-97.

49. Zheng L, Qi T, Yang D, Qi M, Li D, Xiang X, et al. MicroRNA-9 suppresses the proliferation, invasion and metastasis of gastric cancer cells through targeting Cyclin D1 and Ets1. PLoS ONE. 2013;8: e55719. 
50. Deng H, Guo Y, Song H, Xiao B, Sun W, Liu Z, et al. MicroRNA195 and microRNA-378 mediate tumor growth suppression by epigenetical regulation in gastric cancer. Gene. 2013;518:351-9.

51. Gandarillas A. The mysterious human epidermal cell cycle, or an oncogene-induced differentiation checkpoint. Cell Cycle (Georgetown, Tex). 2012;11:4507-16.

52. Schmidt EV. The role of c-Myc in regulation of translation initiation. Oncogene. 2004;23:3217-21.

53. Zhou W, Marcus AI, Vertino PM. Dysregulation of mTOR activity through LKB1 inactivation. Chinese J cancer. 2013;32:427-33.

54. Li W, Jin X, Deng X, Zhang G, Zhang B, Ma L. The putative tumor suppressor microRNA-497 modulates gastric cancer cell proliferation and invasion by repressing eIf4E. Biochem Biophys Res Commun. 2014;449:235-40.

55. Peng W, Chen ZY, Wang L, Wang Z, Li J. MicroRNA-199a-3p is downregulated in gastric carcinomas and modulates cell proliferation. Genet Mol Res GMR. 2013;12:3038-47.

56. Wu W, Takanashi M, Borjigin N, Ohno SI, Fujita K, Hoshino S, et al. MicroRNA-18a modulates STAT3 activity through negative regulation of PIAS3 during gastric adenocarcinogenesis. Br J Cancer. 2013;108:653-61.

57. Qin S, Ai F, Ji W-F, Rao W, Zhang H-C, Yao W-J. miR-19a promotes cell growth and tumorigenesis through targeting SOCS1 in gastric cancer. Asian Pac J Cancer Prev. 2013;14:835-40.

58. Ding L, Xu Y, Zhang W, Deng Y, Si M, Du Y, et al. miR-375 frequently downregulated in gastric cancer inhibits cell proliferation by targeting JAK2. Cell Res. 2010;20:784-93.

59. Wu Q, Yang Z, An Y, Hu H, Yin J, Zhang P, et al. miR-19a/b modulate the metastasis of gastric cancer cells by targeting the tumour suppressor MXD1. Cell Death Dis. 2014;5:e1144.

60. Hsu KW, Wang AM, Ping YH, Huang KH, Huang TT, Lee HC, et al. Downregulation of tumor suppressor MBP-1 by microRNA363 in gastric carcinogenesis. Carcinogenesis. 2014;35:208-17.

61. Sun T, Wang C, Xing J, Wu D. miR-429 modulates the expression of c-Myc in human gastric carcinoma cells. Eur J Cancer. 2011;47: 2552-9.

62. He W, Li Y, Chen X, Lu L, Tang B, Wang Z, et al. miR-494 acts as an anti-oncogene in gastric carcinoma by targeting c-Myc. J Gastroenterol Hepatol. 2014;29:1427-34.

63. Yang F, Xue X, Zheng L, Bi J, Zhou Y, Zhi K, et al. Long noncoding RNA GHET1 promotes gastric carcinoma cell proliferation by increasing c-Myc mRNA stability. FEBS J. 2014;281:802-13.

64. Gao J, Senthil M, Ren B, Yan J, Xing Q, Yu J, et al. IRF-1 transcriptionally upregulates PUMA, which mediates the mitochondrial apoptotic pathway in IRF-1-induced apoptosis in cancer cells. Cell Death Differ. 2010;17:699-709.

65. Yang SJ, Meng JP, Qu Y, Liu YB. The progress on the signal transduction pathways of apoptosis. Chin J Com Med. 2007;17:297301.

66. Sacconi A, Biagioni F, Canu V, Mori F, Di Benedetto A, Lorenzon L, et al. miR-204 targets Bcl-2 expression and enhances responsiveness of gastric cancer. Cell Death Dis. 2012;3:e423.

67. Wei B, Song Y, Zhang Y, Hu M. MicroRNA-449a functions as a tumor-suppressor in gastric adenocarcinoma by targeting Bcl-2. Oncol Lett. 2013;6:1713-8.

68. He XP, Shao Y, Li XL, Xu W, Chen GS, Sun HH, et al. Downregulation of miR-101 in gastric cancer correlates with cyclooxygenase-2 overexpression and tumor growth. FEBS J. 2012;279:4201-12.

69. Gao C, Zhang Z, Liu W, Xiao S, Gu W, Lu H. Reduced microRNA218 expression is associated with high nuclear factor kappa B activation in gastric cancer. Cancer. 2010;116:41-9.

70. Zhao Y, Li C, Wang M, Su L, Qu Y, Li J, et al. Decrease of miR202-3p expression, a novel tumor suppressor, in gastric cancer. PLoS ONE. 2013;8:e69756.
71. Liu X, Ru J, Zhang J, Zhu LH, Liu M, Li X, et al. miR-23a targets interferon regulatory factor 1 and modulates cellular proliferation and paclitaxel-induced apoptosis in gastric adenocarcinoma cells. PLoS ONE. 2013;8:e64707.

72. Saito Y, Suzuki H, Imaeda H, Matsuzaki J, Hirata K, Tsugawa H, et al. The tumor suppressor microRNA-29c is downregulated and restored by celecoxib in human gastric cancer cells. Int $\mathrm{J}$ Cancer. 2013;132:1751-60.

73. Noto JM, Piazuelo MB, Chaturvedi R, Bartel CA, Thatcher EJ, Delgado A, et al. Strain-specific suppression of microRNA-320 by carcinogenic Helicobacter pylori promotes expression of the anti-apoptotic protein Mcl-1. Am J Physiol Gastrointest Liver Physiol. 2013;305:G786-96.

74. Wang Z, Liu M, Zhu H, Zhang W, He S, Hu C, et al. miR-106a is frequently upregulated in gastric cancer and inhibits the extrinsic apoptotic pathway by targeting FAS. Mol Carcinog. 2013;52:63446.

75. Tsukamoto Y, Nakada C, Noguchi T, Tanigawa M, Nguyen LT, Uchida T, et al. MicroRNA-375 is downregulated in gastric carcinomas and regulates cell survival by targeting PDK1 and 14-3-3 zeta. Cancer Res. 2010;70:2339-49.

76. Li C, Nie H, Wang M, Su L, Li J, Yu B, et al. MicroRNA-409-3p regulates cell proliferation and apoptosis by targeting PHF10 in gastric cancer. Cancer Lett. 2012;320:189-97.

77. Li YH, Chen M, Zhang M, Zhang XQ, Zhang S, Yu CG, et al. Inhibitory effect of survivin-targeting small interfering RNA on gastric cancer cells. Genetics Mol Re : GMR. 2014;13:6786-803.

78. Zhao Y, Guo Q, Chen J, Hu J, Wang S, Sun Y. Role of long noncoding RNA HULC in cell proliferation, apoptosis and tumor metastasis of gastric cancer: a clinical and in vitro investigation. Oncol Rep. 2014;31:358-64.

79. Hanahan D, Weinberg RA. Hallmarks of cancer: the next generation. Cell. 2011;144:646-74.

80. Ijaz T, Pazdrak K, Kalita M, Konig R, Choudhary S, Tian B, et al. Systems biology approaches to understanding epithelial mesenchymal transition (EMT) in mucosal remodeling and signaling in asthma. World Allergy Organ J. 2014;7:13.

81. Diaz-Lopez A, Moreno-Bueno G, Cano A. Role of microRNA in epithelial to mesenchymal transition and metastasis and clinical perspectives. Cancer Manag Res. 2014;6:205-16.

82. Pencheva N, Tavazoie SF. Control of metastatic progression by microRNA regulatory networks. Nat Cell Biol. 2013;15: 546-54.

83. Kogo R, Mimori K, Tanaka F, Komune S, Mori M. Clinical significance of miR-146a in gastric cancer cases. Clin Cancer Res Off J Am Assoc Cancer Res. 2011;17:4277-84.

84. Xie J, Chen M, Zhou J, Mo MS, Zhu LH, Liu YP, et al. miR-7 inhibits the invasion and metastasis of gastric cancer cells by suppressing epidermal growth factor receptor expression. Oncol Rep. 2014;31:1715-22.

85. Zhao X, Dou W, He L, Liang S, Tie J, Liu C, et al. MicroRNA-7 functions as an anti-metastatic microRNA in gastric cancer by targeting insulin-like growth factor 1 receptor. Oncogene. 2013;32:1363-72.

86. Deng M, Tang HL, Lu XH, Liu MY, Lu XM, Gu YX, et al. miR-26a suppresses tumor growth and metastasis by targeting FGF9 in gastric cancer. PLoS ONE. 2013;8:e72662.

87. Peng Y, Guo JJ, Liu YM, Wu XL. MicroRNA-34a inhibits the growth, invasion and metastasis of gastric cancer by targeting PDGFR and MET expression. Bioscience reports 2014; 34

88. Lo SS, Hung PS, Chen JH, Tu HF, Fang WL, Chen CY, et al. Overexpression of miR-370 and downregulation of its novel target TGF $\beta$-RII contribute to the progression of gastric carcinoma. Oncogene. 2012;31:226-37. 
89. Li CL, Nie H, Wang M, Su LP, Li JF, Yu YY, et al. MicroRNA-155 is downregulated in gastric cancer cells and involved in cell metastasis. Oncol Rep. 2012;27:1960-6.

90. Liu XJ, Chen ZF, Li HL, Hu ZN, Liu M, Tian AP, et al. Interaction between cyclooxygenase-2, Snail, and E-cadherin in gastric cancer cells. World J Gastroenterol WJG. 2013;19:6265-71.

91. Jia L, Wu J, Zhang L, Chen J, Zhong D, Xu S, et al. Restoration of miR-1228* expression suppresses epithelial-mesenchymal transition in gastric cancer. PLoS ONE. 2013;8:e58637.

92. Carvalho J, van Grieken NC, Pereira PM, Sousa S, Tijssen M, Buffart TE, et al. Lack of microRNA-101 causes E-cadherin functional deregulation through EZH2 up-regulation in intestinal gastric cancer. J Pathol. 2012;228:31-44.

93. Liao YL, Hu LY, Tsai KW, Wu CW, Chan WC, Li SC, et al. Transcriptional regulation of miR-196b by ETS2 in gastric cancer cells. Carcinogenesis. 2012;33:760-9.

94. Song F, Yang D, Liu B, Guo Y, Zheng H, Li L, et al. Integrated microRNA network analyses identify a poor-prognosis subtype of gastric cancer characterized by the miR-200 family. Clin Cancer Res Off J Am Assoc Cancer Res. 2014;20:878-89.

95. Shin JY, Kim YI, Cho SJ, Lee MK, Kook MC, Lee JH, et al. MicroRNA-135a suppresses lymph node metastasis through down-regulation of ROCK1 in early gastric cancer. PLoS ONE. 2014;9:e85205.

96. Song Y, Zhao F, Wang Z, Liu Z, Chiang Y, Xu Y, et al. Inverse association between miR-194 expression and tumor invasion in gastric cancer. Ann Surg Oncol. 2012;19 Suppl 3:S509-17.

97. Zhou L, Zhao X, Han Y, Lu Y, Shang Y, Liu C, et al. Regulation of UHRF1 by miR-146a/b modulates gastric cancer invasion and metastasis. FASEB J Off Publ Fed Am Soc Exp Biology. 2013;27: 4929-39.

98. Jin Z, Selaru FM, Cheng Y, Kan T, Agarwal R, Mori Y, et al. MicroRNA-192 and -215 are upregulated in human gastric cancer in vivo and suppress ALCAM expression in vitro. Oncogene. 2011;30:1577-85.

99. Xu ZY, Yu QM, Du YA, Yang LT, Dong RZ, Huang L, et al. Knockdown of long non-coding RNA HOTAIR suppresses tumor invasion and reverses epithelial-mesenchymal transition in gastric cancer. Int J Biol Sci. 2013;9:587-97.

100. Ruth MC, Xu Y, Maxwell IH, Ahn NG, Norris DA, Shellman YG. RhoC promotes human melanoma invasion in a PI3K/Aktdependent pathway. J Investig Dermatol. 2006;126:862-8.

101. Rath N, Olson MF. Rho-associated kinases in tumorigenesis: reconsidering ROCK inhibition for cancer therapy. EMBO Rep. 2012;13:900-8.

102. Zheng B, Liang L, Wang C, Huang S, Cao X, Zha R, et al. MicroRNA-148a suppresses tumor cell invasion and metastasis by downregulating ROCK1 in gastric cancer. Clin Cancer Res Off J Am Assoc Cancer Res. 2011;17:7574-83.

103. Li P, Chen X, Su L, Li C, Zhi Q, Yu B, et al. Epigenetic silencing of miR-338-3p contributes to tumorigenicity in gastric cancer by targeting SSX2IP. PLoS ONE. 2013;8:e66782.

104. Zuo J, Xia J, Ju F, Yan J, Zhu A, Jin S, et al. MicroRNA-148a can regulate runt-related transcription factor 3 gene expression via modulation of DNA methyltransferase 1 in gastric cancer. Mol Cells. 2013;35:313-9.

105. Qin J, Wu C. ILK: a pseudokinase in the center stage of cell-matrix adhesion and signaling. Curr Opin Cell Biol. 2012;24:607-13.
106. Wang M, Li C, Nie H, Lv X, Qu Y, Yu B, et al. Down-regulated miR-625 suppresses invasion and metastasis of gastric cancer by targeting ILK. FEBS Lett. 2012;586:2382-8.

107. Han TS, Hur K, Xu G, Choi B, Okugawa Y, Toiyama Y, Oshima H, Oshima M, Lee HJ, Kim VN, Chang AN, Goel A, Yang HK. MicroRNA-29c mediates initiation of gastric carcinogenesis by directly targeting ITGB4. Gut 2014

108. Wang $\mathrm{X}, \mathrm{Yu} \mathrm{H}$, Lu X, Zhang $\mathrm{P}$, Wang $\mathrm{M}, \mathrm{Hu}$ Y. miR-22 suppresses the proliferation and invasion of gastric cancer cells by inhibiting CD151. Biochem Biophys Res Commun. 2014;445:175-9.

109. Zhai R, Kan X, Wang B, Du H, Long Y, Wu H, Tao K, Wang G, Bao L, Li F, Zhang W. miR-152 suppresses gastric cancer cell proliferation and motility by targeting CD151. Tumour Biology: the journal of the International Society for Oncodevelopmental Biology and Medicine 2014.

110. Liang S, He L, Zhao X, Miao Y, Gu Y, Guo C, et al. MicroRNA let$7 \mathrm{f}$ inhibits tumor invasion and metastasis by targeting MYH9 in human gastric cancer. PLoS ONE. 2011;6:e18409.

111. Lukaszewicz-Zajac M, Mroczko B, Szmitkowski M. [The significance of metalloproteinases and their inhibitors in gastric cancer]. Postepy Hig Med Dosw (Online). 2009;63:258-65.

112. Guo MM, Hu LH, Wang YQ, Chen P, Huang JG, Lu N, et al. miR22 is down-regulated in gastric cancer, and its overexpression inhibits cell migration and invasion via targeting transcription factor Sp1. Med Oncol. 2013;30:542.

113. Gao P, Xing AY, Zhou GY, Zhang TG, Zhang JP, Gao C, et al. The molecular mechanism of microRNA-145 to suppress invasionmetastasis cascade in gastric cancer. Oncogene. 2013;32:491-501.

114. Zheng L, Pu J, Qi T, Qi M, Li D, Xiang X, et al. miRNA-145 targets v-ets erythroblastosis virus E26 oncogene homolog 1 to suppress the invasion, metastasis, and angiogenesis of gastric cancer cells. Mol Cancer Res MCR. 2013;11:182-93.

115. Zhu M, Zhang N, He S, Lui Y, Lu G, Zhao L. MicroRNA-106a targets TIMP2 to regulate invasion and metastasis of gastric cancer. FEBS Lett. 2014;588:600-7.

116. Zhao H, Wang Y, Yang L, Jiang R, Li W. miR-25 promotes gastric cancer cells growth and motility by targeting RECK. Mol Cell Biochem. 2014;385:207-13.

117. Jiang B, Li Z, Zhang W, Wang H, Zhi X, Feng J, et al. miR-874 inhibits cell proliferation, migration and invasion through targeting aquaporin-3 in gastric cancer. J Gastroenterol. 2014;49:1011-25.

118. Sakamoto N, Naito Y, Oue N, Sentani K, Uraoka N, Zarni Oo H, et al. MicroRNA-148a is downregulated in gastric cancer, targets MMP7, and indicates tumor invasiveness and poor prognosis. Cancer Sci. 2014;105:236-43.

119. Chen H, Li L, Wang S, Lei Y, Ge Q, Lv N, Zhou X, Chen C. Reduced miR-126 expression facilitates angiogenesis of gastric cancer through its regulation on VEGF-A. Oncotarget 2014.

120. Seok JK, Lee SH, Kim MJ, Lee YM. MicroRNA-382 induced by HIF- $1 \alpha$ is an angiogenic miR targeting the tumor suppressor phosphatase and tensin homolog. Nucleic Acids Res. 2014;42:8062-72.

121. Zheng Y, Li S, Ding Y, Wang Q, Luo H, Shi Q, et al. The role of miR-18a in gastric cancer angiogenesis. Hepatogastroenterology. 2013;60:1809-13.

122. Liu L, Yan B, Yang Z, Zhang X, Gu Q, Yue X. ncRuPAR inhibits gastric cancer progression by down-regulating protease-activated receptor-1. Tumour Biology : The Journal of the International Society for Oncodevelopmental Biology and Medicine 2014. 